\title{
O estudante imigrante e o papel do professor de matemática como agente sociocultural e político
}

\author{
The immigrant student and the role of the mathematics teacher as \\ a sociocultural and political agent
}

\author{
Dygianne Batista Vieira \\ Universidade de Brasília - Faculdade de Educação - Departamento de Métodos e Técnicas - MTC \\ lygivieira@gmail.com \\ Geraldo Eustáquio Moreira \\ Universidade de Brasília - Faculdade de Educação - Programa de Pós-graduação em Educação - \\ PPGE/UnB \\ geust2007@gmail.com
}

\begin{abstract}
Resumo: Este artigo tem como objetivo situar o papel do professor de matemática como agente sociocultural e político promotor da inclusão de alunos imigrantes na atividade matemática, bem como no espaço escolar. Nesse sentido, buscamos responder: qual o papel do professor de matemática frente ao fenômeno das migrações? Reconhecendo, fundamentalmente, o professor de matemática como agente sociocultural e político que promove a inclusão de alunos imigrantes. Como embasamento teórico, abordamos as perspectivas de Educar em Direitos Humanos de Candau et al. (2013) e da Educação Matemática Inclusiva de Vieira e Moreira (2018) e para compreendermos os conceitos lugar e território recorremos à geógrafa Doreen Massey $(2000 ; 2008 ; 2017)$ e a Haesbaert $(1997 ; 2014)$. Por fim, concluímos que a postura do professor frente a todas as formas de discriminação e preconceito faz uma profunda diferença no cotidiano dos estudantes. E que a materialização do conhecimento matemático, nesse contexto, tem como possibilidade a resolução de problemas e a investigação matemática que incorporem conteúdos de cunho político e social.
\end{abstract}

Palavras-chave: Territorialidade. Imigração. Direitos Humanos. Inclusão. Educação Matemática.

Abstract: This article aims to situate the role of the mathematics teacher as a sociocultural and political agent promoting the inclusion of immigrant students in the mathematical activity, as well as in the school space. In this sense, we seek to answer: what is the role of the mathematics teacher in the face of the phenomenon of migrations? Recognizing, fundamentally, the mathematics teacher as a sociocultural and political agent that promotes the inclusion of immigrant students. As a theoretical basis, we approach the perspectives of Educating in Human Rights of Candau et al. (2013) and Inclusive Mathematics Education of Vieira and Moreira (2018) and to understand the concepts place and territory we turn to the geographer Doreen Massey $(2000 ; 2008 ; 2017)$ and Haesbaert $(1997 ; 2014)$. Finally, we conclude that the teacher's attitude towards all forms of discrimination and prejudice makes a profound difference in the daily lives of students. And that the materialization of mathematical knowledge, in this context, has as a possibility the resolution of problems and mathematical research that incorporates political and social content.

Keywords: Territoriality. Immigration. Human Rights. Inclusion. Mathematics Education. 


\section{Apresentação}

Este artigo é um diálogo sobre a construção conceitual de lugar e território para entender o direito do imigrante nos deslocamentos territoriais e seus processos de territorialidade nos diferentes espaços, em especial, o espaço da escola, bem como entender essas questões como um direito humano.

Defendemos, nessa perspectiva, que o professor de matemática compreenda seu importante papel nesse processo para promover a inclusão nas aulas de matemática dos alunos imigrantes, estrangeiros ou não, tanto no sentido do conhecimento matemático quanto na promoção da justiça e do respeito às diferenças dentro e fora da escola. Assim, concebemos o professor de matemática como agente sociocultural e político, conceito que será discutido mais adiante.

Julgamos importante a contextualização do fenômeno das migrações para compreendermos o papel do professor diante dele. É fato que as migrações sempre existiram e que, cada vez mais, tem aumentado o número de pessoas que migram de um lado para o outro em todo o globo terrestre. Como afirma Ruble (2013, p. 65), "as pessoas não se movem apenas, assentam num determinado lugar", ou seja, buscam pertencimento ao lugar que migram. De acordo com a Divisão da População das Nações Unidas, cerca de 200 milhões de pessoas (3\% da população) vivem fora do país donde nasceram, verifica-se, portanto, que a população mundial está em constante movimento pelos mais variados motivos.

Diante desse movimento, vive-se uma genealogia dupla, na modernidade ocidental, que dividiu abissalmente o mundo entre sociedades metropolitanas e coloniais (SANTOS, 2009) e essa divisão produziu a invisibilidade das pessoas, dos lugares, dos territórios e das culturas. Essa linha abissal, de acordo com Santos (2014), produz exclusões radicais e diversas, mesmo com o fim do colonialismo, tais como o racismo, a xenofobia e a discriminação com trabalhadores imigrantes indocumentados. É sabido que a escola não se isenta dessas exclusões, em particular, o professor de matemática, que nem sempre se preocupa com o "para quem", mas sim com “o que” deve ser "ensinado".

Numa concepção contra hegemônica e intercultural de direitos humanos, que reconhece a diversidade global e não se reduz a compreensão ocidental da universalidade dos direitos humanos, buscamos enfatizar que, diante do fluxo rápido de pessoas da sociedade contemporânea, os povos, as comunidades e as nações devem aceitar, respeitar e acolher a diferença que vem de diversos 
lugares do mundo. Dessa forma, "as comunidades urbanas precisam de ampliar o seu conjunto de respostas para a diversidade, a fim de acomodar os recém-chegados, assim como os imigrantes se devem adaptar ao novo ambiente" (RUBLE, 2013, p. 66).

Diante deste movimento migratório de pessoas de todos os lugares e culturas, será possível compreender o sentido de lugar como local, particular, coerente e homogêneo? Compreendemos que não, pois a fragmentação geográfica e a ruptura espacial têm modificado a forma de enxergarmos o "lugar" de pertencimento das pessoas. Para Massey (2000), a busca da coerência e da homogeneidade dos "lugares" dá origem às reações defensivas e reacionárias entre os povos e às certas formas de nacionalismo, tais como: recuperação sentimentalizada de "heranças" saneadas e de completo antagonismo aos que chegam e aos "estranhos".

Para essa autora, é equivocado pensar que esta identidade do lugar (sentido de lugar) se constrói a partir de uma história introvertida, voltada para dentro. Nessa visão, exige-se um traçado de fronteiras que busca evitar a "mistura", no entanto, evitar a mistura é não reconhecer, diante do itinerário das pessoas, as múltiplas identidades existentes.

A escola, como um dos espaços que recebe o imigrante, necessita compreender esses contextos e se preparar para a acolhida, assim como os professores devem realizar ações capazes de melhorar a situação desse aluno, levando-o a se sentir confortável e incluído no processo educativo.

Rodovalho, Moreira e Mané (2018) consideram que os professores nem sempre possuem formação necessária para lidarem com os alunos com Necessidades Educativas Específicas (NEE), como é o caso dos alunos imigrantes e, por isso, podem não estar preparados para promoverem a educação inclusiva.

Posto isso, compreendemos que a migração é um direito humano que inclui o direito à educação de qualidade no lugar estabelecido pelo imigrante como moradia, seja em um país, um estado ou uma cidade diferente da sua origem. Nesse cenário, objetivamos situar o papel do professor de matemática como agente sociocultural e político promotor da inclusão de alunos imigrantes na atividade matemática, bem como no espaço escolar em sua totalidade.

Em seguida, faremos uma discussão sobre as migrações e territorialidade como um direito humano, para depois apresentarmos o professor de matemática como agente essencial no ambiente escolar que acolhe o aluno imigrante. 


\section{Sociedade contemporânea e as migrações}

A sociedade tem passado, nas últimas décadas, por rápidas e profundas transformações sociais, econômicas e culturais e, nesse rol de transformações, a questão das migrações tem sofrido mudanças expressivas. Como fator influenciador, a globalização e as políticas liberais que abriram as nações para o livre mercado em suas relações econômicas, no entanto, os bloqueios multiplicaram-se quando se trata do livre acesso às pessoas nas fronteiras geográficas, nas quais a entrada somente é permitida para aqueles que possuem a necessária "senha de acesso".

A busca de muitas pessoas por lugares que lhe ofereçam melhores condições de vida tem aumentado, cada vez mais, e por diversos motivos. Seja por questões voluntárias, seja por questões de refúgio, fato é que as pessoas têm se movimentado de um lado para o outro em todo o globo terrestre. Mesmo que mais expressivamente nos dias atuais, como mencionado, esse não é um fenômeno recente.

Levando-se em conta o fato de que o homo sapiens surgiu no continente africano e depois dominou todas as áreas do planeta, podemos afirmar que a migração sempre esteve presente na história da humanidade e, preliminarmente, é a movimentação dos homens pelo território (SILVA, 2009, p. 20).

A partir da revolução industrial, no século XVIII, e da transformação do povo em proletariado, o novo modo de produção, que se tornava hegemônico, permitiu novas perspectivas de vida e fez com que as migrações se intensificassem, pois os países mais industrializados necessitavam de mão de obra e, por isso, abriram suas fronteiras para esse trabalhador.

Como justifica Silva (2009), o processo de migrações, como nunca visto em períodos anteriores, foi iniciado, principalmente, pelo desenvolvimento tecnológico trazido pela revolução e os meios de transportes que se tornaram regulares e mais baratos. Hobsbawm (2002) acrescenta que os movimentos populacionais e a industrialização andam juntos, pois o desenvolvimento econômico moderno pede mudanças substanciais junto aos povos facilitando, assim, tais movimentos.

Para Magalhães (2010, p. 35), as análises predominantes, nos anos 80 e 90, justificavam as migrações pelo "jogo de forças globais que fugiam à vontade do migrante, enxergando os fluxos migratórios como resultados de conjunturas que expulsam enquanto outras atraem”. Assim, para essa autora, a complexidade dos movimentos não é redutível somente à lei da oferta e da procura, para ela não devemos olhar os imigrantes simplesmente como "vítimas” de relações que fogem ao seu domínio. "O que não quer dizer que, para a compreensão das migrações contemporâneas, não 
seja importante levar-se em conta as relações sistêmicas” (MAGALHÃES, 2010, p. 36). Além disso, a autora acrescenta que, nesse processo, existe ainda a escolha das pessoas em querer migrar.

Diante do exposto, compreendemos que os fluxos migratórios são, muitas vezes, gerados por crises econômicas, no entanto, eles não explicam "a autonomização dos movimentos migratórios em relação às conjunturas que os originaram” (PERALVA, 2008, p. 19). Ou seja, a mobilidade e a permanência das pessoas que migram "tem um forte componente de autonomia dos sujeitos imigrantes” (MAGALHÃES, 2010, p. 36). Com isso, enfatizamos que a autonomia do imigrante é um direito de cidadania, ou seja, um direito humano.

No âmbito educativo, Véras (2019, p. 305) ao tratar da obra de Rodrigues (2017) sinaliza que "a experiência migrante envolve novas (re)identificações, a pluridiversidade, a questão da língua, dos valores e dos símbolos da nação de origem e as do país receptor. Tudo repercute na escolarização, sobretudo na alfabetização".

Compreensão de territorialidade para o reconhecimento das migrações como um direito humano

Compreendendo as migrações como um direito, existem normas e instituições internacionais que amparam o imigrante, como: a Organização Internacional do Trabalho (OIT), a Convenção Internacional sobre a Proteção dos Direitos de todos os Trabalhadores Migratórios e de seus Familiares (ONU, 1990) e a Corte Interamericana de Direitos Humanos. Além dessas instituições, a Declaração Universal dos Direitos Humanos, de 1948, diz, nos artigos XIII e XV, que todo ser humano tem direito a deixar qualquer país, inclusive o próprio, e a este regressar; e ninguém será arbitrariamente privado de sua nacionalidade, nem do direito de mudar de nacionalidade.

Estamos diante, portanto, de questões de escolha, de autonomia e de liberdade de deslocamento nos mais diversos territórios. Um direito que os Estados devem se responsabilizar, garantir e promover às pessoas que migram. Essa questão de direito será mais explorada nos próximos parágrafos quando definirmos o sentido global de lugar e territorialidade.

O conceito progressista de lugar compreende que ele é absolutamente não estático. "Se os lugares podem ser conceituados em termos das interações sociais que agrupam, então, essas interações em si mesmas não são inertes, congeladas no tempo: elas são processos” (MASSEY, 2000, p. 184). Assim, o conceito de lugar está, ao longo do tempo, em constantes modificações. 
Consoante a geógrafa Doreen Massey (2000), compreendemos que o sentido de lugar só pode ser constituído por meio da ligação desse lugar com outros lugares e jamais de forma isolada, internalizada, de dentro para fora. Na visão progressista de lugar, não existe ameaça em reconhecer o sentido global de lugar, no entanto, essa é uma discussão polêmica nos países autoproclamados “desenvolvidos" que negam a diversidade e a complexidade da constituição desses lugares.

É evidente que barreiras físicas, políticas e simbólicas são criadas para evitar que pessoas de outros lugares entrem nas limitações de determinado território/lugar. Nesse contexto, surge o indivíduo que não é contemplado pelos direitos nos países que migraram e, por consequência, as desigualdades são acentuadas pela falta de regularização e reconhecimento desses direitos, que levam o imigrante, muitas vezes, ao subemprego.

Doreen Massey defende o reconhecimento da contemporaneidade de múltiplas trajetórias históricas, ou seja, se trata de reconhecer a coexistência de outros, com trajetórias históricas próprias, que se cruzam, se conectam e se desconectam formando, assim, o espaço a partir dessas relações. Um lugar onde ele próprio se forme como um feixe dessas articulações (MASSEY, 2008).

$\mathrm{Na}$ inexistência desse lugar, permanecemos em um abismo de desigualdade gerando incompreensão, violência e confronto entre povos e nações. No qual cada um defende o seu território, sem abertura para negociação e respeito ao estrangeiro. O que falta, muitas vezes, como aponta Massey (2017), é a vontade de negociar.

Avançando um pouco mais nos conceitos, o território adquire novos significados com as reivindicações de identidades territoriais mais fluidas, individuais e de base cultural (CLAVAL, 2014). Assim, a concepção de espaço deve superar a perspectiva de ser fixo e inerte para ser um espaço mais dinâmico e fluido. De acordo com essa ideia, concebemos o território numa abordagem contemporânea, Fuini (2017) explica que essa concepção entende que os sujeitos sociais também constroem, negociam e lutam por seus territórios, que é uma luta cultural, com discursos, representações, identidades e simbolismos mobilizadores de espaços subnacionais ou partes deste subespaço.

A concepção de território dada por Santos (1994) está de acordo com a abordagem contemporânea e supera a visão moderna de Estado territorial que definia e moldava os lugares, o autor reflete agora a ideia de mais de uma dimensão para compreender o território, pelo imaterial (normas, controles, sistemas de engenharia, movimentos e circulação) e escalas articuladas pelas verticalidades (lugares vizinhos reunidos por uma continuidade territorial) e horizontalidades (formadas por pontos distantes uns dos outros, ligados por todas as formas e processos sociais). Nesse sentido, o território extrapola a ideia de "cercado" que é definido pelo Estado. 
Assim, o território é uma construção contemporânea das multiterritorialidades e territórios múltiplos, apropriação espacial em territórios-rede e territórios em rede e a sobreposição de territorialidades no mesmo espaço físico (HAESBAERT, 2014). Nessa mesma perspectiva, Saquet (2009) define territorialidade:

\footnotetext{
A territorialidade corresponde ao poder exercido e extrapola as relações políticas envolvendo as relações econômicas e culturais, indivíduos e grupos, redes e lugares de controle, mesmo que seja temporário, do e no espaço geográfico com suas edificações e relações. A territorialidade efetiva-se em todas as nossas relações cotidianas, ou melhor, ela corresponde às nossas relações sociais cotidianas em tramas, no trabalho, na família, na rua, na praça, na igreja, no trem, na rodoviária, enfim, na cidade-urbano, no rural agrário e nas relações urbano-rurais de maneira múltipla e híbrida (SAQUET, 2009, p. $90)$.
}

Haesbaert (1997) afirma que conceber o território como espaço de identidade cultural é fundamental na sociedade contemporânea em relação ao debate multiculturalista que defende o respeito às diferentes culturas.

Resumindo, as pessoas têm o direito do deslocamento e da instalação nos múltiplos territórios do planeta, seja por autonomia ou por força, o direito de ir e vir deve ser respeitado nas relações da contemporaneidade e a diversidade/diferença e suas multiterritorialidades reconhecidas nos espaços.

Diante desse cenário, o espaço da escola é o lugar de acolhida e de respeito à cultura dos estudantes imigrantes e o professor constitui a efetivação dessa prática. Especificamente, o professor de matemática necessita reconhecer a diversidade e as particularidades existentes na sala de aula para apresentar a matemática de forma inclusiva, respeitando o conhecimento que o aluno imigrante traz de sua história e que isso seja o ponto de partida para sua prática pedagógica. Além disso, sua postura como agente sociocultural e político não permitirá que manifestações de preconceito, de discriminação e de violência sejam praticadas em sala de aula.

Para entendermos essa postura do professor frente ao fenômeno das migrações, faremos, a seguir, a explanação do que entendemos dele ser um agente sociocultural e político.

\section{O professor de matemática como agente sociocultural e político em contexto de estudantes imigrantes}

$\mathrm{Na}$ concepção de escola democrática que contribui para o exercício da cidadania e da dignidade de toda pessoa humana, concebemos o professor como agente sociocultural e político que pressupõe, segundo Giroux e McLaren (1994), situar-se em uma ótica contra hegemônica que 
desenvolva processos críticos de compreensão e de ação na realidade para propiciar a criação de uma mentalidade diferente.

Desenvolver uma educação pautada nesses princípios pressupõe uma formação que vai além da informação, uma educação libertadora que exige o desenvolvimento de processos formativos que permitam a sensibilização para práticas de mudança de mentalidades, de valores e de comportamentos (CANDAU et al. 2013). Assim, o professor como agente sociocultural e político tem o desafio de desenvolver uma "pedagogia do empoderamento", que é uma pedagogia crítica e democrática orientada para a mudança pessoal e social (SACAVINO, 2009).

Para Candau et al. (2013), este enfoque pedagógico do empoderamento significa relacionar o crescimento individual com a dinâmica social e com a vida pública, com intuito de promover o desenvolvimento de habilidades, de conhecimentos e de atitudes de questionamento crítico em relação às injustiças, às desigualdades, às relações de poder, às discriminações e à mudança social.

No caso dos alunos imigrantes, a inclusão pautada nesses princípios é o que defendemos. Vieira e Moreira (2018, p. 159) explicam a postura do professor de matemática frente ao desafio da inclusão escolar,

\begin{abstract}
A postura do professor deveria ser pela valorização da diversidade, da pluralidade, da discussão e da reflexão das problemáticas vivenciadas, do combate a qualquer forma de violência na escola e fora dela, no entanto, a realidade mostra que o professor, muitas vezes, viola esses direitos, seja pelo seu silêncio ou pelo próprio ato de violência. Por isso, para que se rompa com o silenciamento e a negação dos vários tipos de violação dos Direitos Humanos nas escolas, há que se atentar para as práticas existentes entre alunos e professores.
\end{abstract}

Não raro, situações de violência são práticas naturalizadas por professores e estudantes. Sobre isso, os autores Vieira e Moreira (2018, p. 159) afirmam que,

\footnotetext{
Dentro da escola, as relações deveriam expressar respeito ao próximo, de forma a valorizar atitudes de amizade, de harmonia e de integração das pessoas. De acordo com o Instituto Brasileiro de Geografia e Estatística - IBGE, que fez um estudo sobre a saúde do estudante brasileiro em 2015, o número de casos de humilhação na escola cresce, a cada dia, quase a metade dos alunos entrevistados na pesquisa (46,6\%) afirmou que já sofreu algum tipo de bullying e que se sentiu humilhado por colegas da escola.
}

Episódios de discriminação e de violência nas escolas é ainda maior quando se trata do imigrante, Véras (2019, p. 310) explica a relação de segregação existente afirmando que "nesse espaço escolar e social, os nacionais sentem-se ameaçados pela presença de imigrantes, especialmente quando estes ascendem socialmente. Há tensões e conflitos que promovem baixa autoestima nos estrangeiros, como reflexo das relações de alteridade”. 
Diante desses fatos, o professor precisa reconhecer seu papel como agente sociocultural e político, esse tipo de atitude está baseado em uma pedagogia orientada à mudança pessoal e social (SACAVINO, 2009). Nas palavras de Candau et al. (2013, p. 38), essa perspectiva se trata de ações que potencializam "grupos ou pessoas que têm menos poder na sociedade e que estão dominados, submetidos ou silenciados, em relação à vida e aos processos sociais, políticos, econômicos, culturais etc.".

E o professor de matemática nesse contexto? Como se dá a pedagogia do empoderamento pautada nesse perfil de professor? Entendemos que os estudantes precisam desenvolver não apenas o conhecimento pragmático sobre como usar matemática e como construir modelos, mas também desenvolver o conhecimento sobre as precondições para a construção do modelo que deve ser voltado para o entendimento das funções sociais de aplicações de modelos matemáticos (SKOVSMOSE, 2013).

A matemática aqui defendida busca uma educação que seja crítica, que discuta condições básicas para a obtenção do conhecimento, que esteja situada nos problemas sociais, nas desigualdades, na supressão, entre outros. E o professor, fazendo uso dos atributos da matemática, busca reconhecer a educação como uma força social progressivamente ativa reagindo às contradições sociais.

O professor de matemática como agente sociocultural e político é o sujeito que inclui, que busca alcançar todos os estudantes sem distinção, que reconhece a diversidade e promove práticas educativas para que os estudantes se percebam incluídos no processo de ensino e de aprendizagem.

Para isso, é necessário desenvolver práticas pedagógicas de empoderamento, de autonomia e de formação para a cidadania do estudante imigrante ou não. A materialização do conhecimento matemático se dá pela resolução de problemas e pela investigação matemática que incorporem conteúdos de cunho político e social, visando a "transformação da realidade em espaços de construção democrática com justiça social” (CANDAU et al., 2013, p. 51). Além disso, a postura do professor frente a todas as formas de discriminação e preconceito faz a diferença no cotidiano dos estudantes que passam a se sentirem mais seguros e acolhidos pela escola, pelos professores e, principalmente, pelos estudantes.

\section{Necessidades Educativas Específicas e o aluno imigrante}

É cada vez maior o número de matrículas de outras nacionalidades em escolas brasileiras, de acordo com os dados do Censo Escolar (2008 - 2016), esse número saltou de 34 mil para quase 
73 mil matrículas nesse período. Por isso, é consenso reconhecer a importância de ações de integração desses alunos no sistema de ensino brasileiro. Será que essas ações envolvem apenas o acesso à escola e à sua permanência? Basta matricular o estudante e colocá-lo em sala de aula?

Quando se trata de inclusão, não estamos apenas referindo que este aluno estrangeiro ou de outro estado brasileiro esteja matriculado na escola, mas sim que ele seja integrado e acolhido por todos e, obviamente, que participe do processo de ensino e de aprendizagem de forma significativa.

Desejamos, em especial, que o professor de matemática garanta aulas que incluam, integrem e proporcionem a esse aluno condições de permanência na escola. Alinhando-nos a Rodovalho, Moreira e Mané (2018, p. 259), acreditamos que,

[...] se o professor ousar propiciar interações que permitam ao aluno a construção de uma melhor autoestima e autoconfiança, assim como proporcionar vivências geradoras de sentidos e significados que proporcione o desenvolvimento de novas configurações subjetivas, provavelmente o aluno terá condições de enfrentar melhor as dificuldades que surgem ao longo do processo educativo.

O professor, nesse contexto, é agente sociocultural e político que promove o empoderamento desses estudantes dando a eles condições de completar os estudos na educação básica para, futuramente, poderem ingressar no ensino superior. Essa perspectiva é a de uma educação democrática, na qual afirma Monteiro (2011, p. 14) o professor deve ter a postura de aceitação desses alunos em sala de aula,

\footnotetext{
Para que essa educação democrática aconteça é fundamental que os professores tenham uma postura de aceitação quanto à diversidade, que conheçam verdadeiramente e que se interessem por todos os alunos com que trabalham sendo alguns ditos diferentes, que se moldem perante os diferentes desafios que esses alunos com Necessidades Educativas Especiais the irão colocar e que atuem de forma colaborativa com toda a comunidade escolar.
}

Diante disso, a educação inclusiva precisa ser compreendida de uma forma mais ampla e não deve ser reduzida apenas aos alunos com deficiência. Melhor dizendo, os alunos com Necessidades Educativas Específicas (NEE) não se referem apenas aos que têm dificuldade de aprendizagem devido a alguma deficiência física ou mental, mas sim a qualquer estudante que necessita de ação pedagógica específica. Dessa forma, o imigrante integra o rol de estudantes com NEE como explicam Rodovalho, Porto e Moreira (2016, p. 54), 


\begin{abstract}
Normalmente fala-se em necessidades educacionais especiais quando um aluno possui algum tipo de deficiência ou insuficiência física ou mental, revelando alguma dificuldade de aprendizagem. No entanto, é bastante comum que alunos apresentem algum grau de dificuldade de aprendizagem, sem possuir qualquer deficiência física ou mental. Em um sentido bem mais amplo, todos nós apresentamos alguma NEE, pois temos nossas idiossincrasias e, portanto, podemos estar mais ou menos adaptados de acordo com o contexto sócio-histórico-cultural vigente.
\end{abstract}

O estudante imigrante, que revela alguma dificuldade de aprendizagem seja por dificuldades com o idioma, seja por questões sociais ou culturais, seja por falta de empoderamento ou por qualquer outra questão, deve ser reconhecido pelo professor que precisa compreender esses processos e integrar plenamente o estudante para que este possa alcançar a aprendizagem nos diferentes contextos necessários para sua inclusão na atividade matemática e nos espaços da escola.

\title{
Considerações finais
}

Apresentamos, neste artigo, questões sobre a sociedade contemporânea que interferem na disputa territorial e fizemos uma breve construção conceitual de lugar e território para entendermos o direito do imigrante e seus processos de territorialidade nos diferentes espaços. Além disso, situamos o professor de matemática como agente sociocultural e político frente ao fenômeno das migrações.

Para compreendermos a situação das migrações como um direito e as barreiras físicas e simbólicas como injustificáveis, partimos do fundamento que os lugares não são estáticos, que não têm identidades e que são processos (MASSEY, 2000; 2017). Nesse sentido, conceber o sentido global de lugar não deveria ser uma ameaça nem reconhecer a coexistência do outro deveria ser uma desconstrução da "herança cultural" dos lugares.

Neste movimento de construir e reconstruir territórios (DELEUZE; GUATTARI, 2008), os imigrantes têm o direito ao território como um direito humano, por isso ele deve ser acolhido, respeitado e, principalmente, possibilitado de gozar dos direitos como qualquer cidadão residente.

Compreendemos que o território não pode ser concebido como espaço de pertencimento somente de pessoas que "herdaram" esse espaço, mas sim que esse lugar precisa ser compreendido como espaço cultural de identificação e de pertencimento de qualquer pessoa que se assenta no território. Este que, muitas vezes, é o lugar da xenofobia responsável pelo agravamento das desigualdades sociais e pela negligência aos direitos humanos. 
Nesse contexto, reforçamos que o professor de matemática como agente sociocultural e político deve compreender o fenômeno das migrações no âmbito regional, estadual e internacional para que possa exercer seu papel como promotor da transformação social, para isso é fundamental que suas aulas tenham como ponto de partida a diversidade cultural e social existente, que a atividade matemática seja pautada em questões político-sociais de interesse dos sujeitos inseridos no processo de aprendizagem.

Além disso, reconhecemos que a matemática é uma disciplina de caráter excludente, pois evidencia práticas pedagógicas de reprodução, supervalorização de regras e de procedimentos, apresentada, muitas vezes, descontextualizada da realidade dos alunos. Por essa razão requer uma nova aparência, uma nova concepção e, principalmente, uma nova abordagem pedagógica.

No caso dos estudantes imigrantes, realidade, cada vez mais, presente em sala de aula, é urgente a inclusão efetiva na atividade matemática no que se refere à contextualização de temas político-sociais que promovam o empoderamento desses estudantes, valorizando sua cultura e seus conhecimentos. É fato que, na maioria das vezes, esses estudantes necessitam de ações educativas específicas, mas essas ações não podem ser reduzidas ao conteúdo da disciplina ensinada e sim da integração desse estudante em todo o espaço escolar. Tudo isso configura, em nosso entendimento, como um direito humano.

Encerramos enfatizando que o professor de matemática deve ter o compromisso educativo de integrar o estudante imigrante nas aulas promovendo o empoderamento desses sujeitos para que isso possa transformar a realidade e fazer justiça social em contexto escolar e fora dele. Sendo, na coexistência, a oportunidade de fazermos uma educação mais justa e mais humana.

\section{Referências}

BRASIL. Instituto Nacional de Estudos e Pesquisas Educacionais Anísio Teixeira. Censo Escolar de 2008. Disponível em:

http://portal.inep.gov.br/web/guest/sinopses-estatisticas-da-educacao-basica . Acesso em: 20 de jan. 2020.

BRASIL. Instituto Nacional de Estudos e Pesquisas Educacionais Anísio Teixeira. Censo Escolar de 2016. Disponível em:

http://portal.inep.gov.br/web/guest/sinopses-estatisticas-da-educacao-basica . Acesso em: 20 de jan. 2020.

CANDAU, Vera Maria et al. Educação em Direitos Humanos e formação de professores (as). São Paulo: Cortez, 2013. 
CLAVAL, Paul. Epistemologia da Geografia. Tradução: Margareth C. A. Pimenta e Joana A. Pimenta. 2a . Ed. Florianópolis, EdUFSC, 2014.

DELEUZE, Gilles; GUATTARI, Félix. O anti-édipo: capitalismo e esquizofrenia. Vol. 1. Lisboa, Portugal: Assírio e Alvim, 2008.

FUINI, Lucas Labigalini. O território em Rogério Haesbaert: concepções e conotações. Geografia, Ensino \& Pesquisa, Santa Maria (RS), Vol. 21, n.1, pp. 19-29, 2017.

GIROUX, Henry; McLAREN, Peter. Formação do professor como uma esfera contrapública: a Pedagogia Pedagogia Radical como uma forma de Política Cultural. In: MOREIRA, A.F. \& SILVA, T. T. (orgs): Currículo, Cultura e Sociedade. São Paulo: Cortez, 1994.

HAESBAERT, Rogério. Viver no limite: território e multi/transterritorialidade em tempos de insegurança e contenção. Rio de Janeiro: Bertrand, 2014.

HAESBAERT, Rogério. Des-territorialização e identidade: a rede gaúcha no Nordeste. Niterói, RJ: Eduff, 1997.

HOBSBAWM, Eric. A era do capital: 1848 - 1875. São Paulo: Paz e Terra, 2002.

MASSEY, Doreen. O sentido global do lugar. In: ARANTES, Antonio A. (org.). O espaço da diferença. Campinas, SP: Papirus, 2000.

MASSEY, Doreen. Pelo espaço: uma nova política da especialidade. Rio de Janeiro: Bertrand Brasil, 2008.

MASSEY, Doreen. A mente geográfica. GEOgraphia, Niterói (RJ), Vol.19, n. 40, pp. 36-40, 2017.

MAGALHÃES, Giovanna Modé. Fronteiras do Direito Humano à Educação: um estudo sobre os imigrantes bolivianos nas escolas públicas de São Paulo. 182f, 2010. Dissertação (Mestrado em Educação) - Universidade de São Paulo, Programa de pós-graduação em Educação. São Paulo, 2010.

MONTEIRO, Susana Maria Da Silva. A atitude dos professores como meio de inclusão de alunos com Necessidades Educativas Especiais. 95f, 2011. Dissertação (Mestrado em Educação Especial) - Escola Superior de Educação Almeida Garrett. Lisboa, 2011.

ORGANIZAÇÕES DAS NAÇÕES UNIDAS. Convenção Internacional sobre a Proteção dos Direitos de Todos os Trabalhadores Migrantes e dos Membros das suas Famílias. Adotada pela Resolução 45/158, de 18 de Dezembro de 1990. Disponível em:

https://treaties.un.org/pages/ViewDetails.aspx?src=TREATY\&mtdsg_no=IV13\&chapter=4\&lang=en. Acesso em: 15 fev. 2020.

ORGANIZAÇÃO DAS NAÇÕES UNIDAS. Declaração Universal dos Direitos Humanos. Adotada e proclamada pela resolução 217 A (III) da Assembléia Geral das Nações Unidas em 10 de dezembro de 1948. Disponível em:

https://www.ohchr.org/EN/UDHR/Documents/UDHR_Translations/por.pdf. Acesso em: 09 jan. 2020. 
PERALVA, Angelina. Globalizạ̧ão, migrações transnacionais e identidades nacionais. Coesão Social na América Latina - Bases para uma nova agenda democrática. Corporación de Estudios para Latinoamérica e Instituto Fernando Henrique Cardoso, São Paulo, Brasil/Santiago de Chile, 2008. Disponível em: https://fundacaofhc.org.br/files/papers/436.pdf. Acesso em: 15 fev. 2020.

RODOVALHO, Maurício Resende; MOREIRA, Geraldo Eustáquio; MANÉ, Djiby. Concepções de professores sobre educação inclusiva no ensino superior privado. EccoS - Rev. Cient., São Paulo, n. 45, p. 255-272, jan./abr. 2018.

RODOVALHO, Maurício Resende; PORTO, Marcelo Duarte; MOREIRA, Geraldo Eustáquio. Inclusão no ensino superior privado: o caso das senhoras que retornam às salas de aula depois de anos de afastamento. Revista De Magistro de Filosofia, v. 20, p. 52-63, 2016. Disponível em: http://catolicadeanapolis.edu.br/revistamagistro/?page_id=701. Acesso em: 15 jan. 2020.

RODRIGUES, Leda Maria de Oliveira (org.). Imigração atual: dilemas, inserção social e escolarização: Brasil, Argentina, EUA. São Paulo: Escuta, 2017. Resenha de: VÉRAS, Maura Pardini Bicudo. Paradoxos na educação: inserção e alteridade de imigrantes nas relações escolares. Revista e-Curriculum, São Paulo, v.17, n.1, p. 304-312 jan./mar. 2019. Disponível em: http://revistas.pucsp.br/curriculum/article/view/38760. Acesso em: 15 fev. 2020.

RUBLE, Blair. Lidar com a heterogeneidade: migrações, alterações demográficas e consequências culturais. In: Eulàlia. Bosh (Ed.). Educação e vida urbana: 20 anos de cidades educadoras. Torres Novas, Portugal: Almondina, 2013.

SACAVINO, Suzana. Democracia e Educação em Direitos Humanos na América Latina. Petrópolis: DP\&A; De Petrus, Rio de Janeiro: Editora Nova América, 2009.

SANTOS, Boaventura de Sousa. Se Deus fosse um ativista dos direitos humanos. São Paulo: Cortez, 2014.

SANTOS, Boaventura de Sousa. Para além do pensamento abissal: das linhas globais a uma ecologia de saberes. In: SANTOS, Boaventura de Sousa; MENESES, Maria Paula (orgs.). Epistemologias do Sul. São Paulo: Cortez, 2009.

SANTOS, Milton. O retorno do território. In: SANTOS, Milton; SOUZA, Maria A. A.; Silveira, Maria L. (orgs.). Território: globalização e fragmentação. São Paulo: Hucitec/Anpur, 1994.

SAQUET, Marcos Aurélio. Por uma abordagem territorial. In: SAQUET, Marcos Aurélio; SPOSITO, Eliseu S. (org.). Território e territorialidades: teoria, processos e conflitos. São Paulo: Expressão Popular, 2009.

SILVA, João Carlos Jarochinski. A imigração ilegal e o direito internacional. 113f, 2009. Dissertação (Mestrado em Direito Internacional) - Universidade Católica de Santos, Programa de PósGraduação em Direito Internacional. Santos (SP), 2009.

SKOVSMOSE, Ole. Educaşão matemática crítica: A questão da democracia. $6^{\mathrm{a}} \mathrm{ed}$. Campinas - SP: Papirus, 2013. 
VIEIRA, Lygianne Batista; MOREIRA, Geraldo Eustáquio. Direitos Humanos e Educação: o professor de matemática como agente sociocultural e político. Revista de Educaşão Matemática, v. 15, p. 548-564, 2018. Disponível em: file://C:/Users/CPD/Downloads/174-577-1PB\%20(1).pdf. Acesso em: 15 fev. 2020.

Recebido em: 29 fev. 2020 / Aprovado em: 19 mar. 2020

Cite como (ABNT NBR 6023: 2018)

VIEIRA, Lygianne Batista; MOREIRA, Geraldo Eustáquio. O estudante imigrante e o papel do professor de matemática como agente sociocultural e político. Dialogia, São Paulo, n. 34, p. 185199, jan./abr. 2020. Disponível em: https://doi.org/10.5585/Dialogia.N34.16711. 